\title{
Selecting Microfilm for Digital Preservation: A Case Study from Project Open Book
}

\section{Paul Conway}

\begin{abstract}
Project Open Book is Yale University Library's multiyear, multifaceted study exploring the feasibility of converting preservation microfilm to digital imagery and enhancing both physical and intellectual access to the resulting collection of digital files. Selection is the central intellectual challenge; challenges are outlined from Yale's case study that will also have bearing on content-oriented selection for digital conversion of books that have been microfilmed in the nation's Brittle Books Program. The approach outlined here for building a digital library from microfilm of the nation's most important brittle books places collection managers under the same umbrella with the other parties interested in creating and then preserving the availability of digital resources. The lessons from Project Open Book about selection of microfilm point to very concrete and achievable solutions for everyone involved in preservation microfilming and the digital conversion of that film.
\end{abstract}

P Library's multiyear, multifaceted study exploring the feasibility of converting preservation microfilm to digital imagery and enhancing both physical and intellectual access to the resulting collection of digital files (Waters 1991; Waters and Weaver 1992; Conway and Weaver 1994). Over the past four years, the library and archives community has discovered through this project the complexities of many aspects of digital imaging technology. In particular, the project served as a catalyst for finding ways to establish meaningful partnerships with the commercial sector, to maximize the quality and minimize the cost of digital conversion of microfilm, and, most recently, to make large and complex digital files available on the Internet.

Selection is the central intellectual challenge of any program that has a goal of creating a corpus of useful and meaningful digital research materials. Selection for digital conversion is like a coin. One face is the set of technical constraints that limits the usefulness of the technology for preservation and access. The other face is the set of issues relating to the content of the materials selected for conversion. To ignore either face of the coin in the selection process shortchanges our patrons.

PAUL Conway is Head, Preservation Department, Yale University Library (pconway@ yalevm.cis.yale.edu). This article is based on a presentation to a joint program meeting of the Collection Management and Development Section and Preservation and Reformatting Section, Association for Library Collections \& Technical Services, at the ALA Annual Conference, Chicago, Illinois, June 26, 1995. Manuscript received September 1, 1995; accepted for publication October 17, 1995. 
My purpose is to outline the challenges Yale faced, and that other libraries will face, in content-oriented selection for digital conversion of books that have been microfilmed in the nation's Brittle Books Program. A complex of ideas and theories together forms the context within which selection from a large collection of preservation microfilm must take place. The selection process for Project Open Book had to involve reconciliation of a theory of what ought to be done with the realities of the scope of the actual microfilm collection. I conclude with a series of recommendations, ranging from the mundane to the complex, for building a meaningful digital library from previously microfilmed materials. A forthcoming report on the latest phase of Project Open Book will review image quality, including a full discussion of technical limitations of microfilm conversion, and the costs of digital conversion from microfilm, including recommendations on controlling or reducing those costs.

\section{NeH Brittle Books Program}

The point of departure for Project Open Book is the ongoing federal government program administered by the National Endowment for the Humanities (NEH) known as the Brittle Books Program. The goal of the program is to preserve on microfilm three million crumbling books selected from high-quality research collections (Farr 1992). In the mid 1980s, the Commission on Preservation and Access arrived at the figure of three million endangered volumes through a complex and partly arbitrary process. First, they estimate the total number of unique volumes of possible enduring value to scholars. Finding the resulting ten million figure too daunting, the commission suggested a project goal of saving one-third. The U.S. Congress agreed to support a twenty-year effort to accomplish this goal and charged $\mathrm{NEH}$ with overseeing the selection and preservation process.

The overall selection strategy of the Brittle Books Program calls for participating libraries to identify large, significant subject-oriented humanities research collections rich with publications from the nineteenth and early twentieth centuries. Collection subject areas run the gamut of humanities disciplines-art, literature, history, and social studies-across time and geography. In most cases the collections are recognized by scholars and by the library community as having extraordinary past, present, and future research value (Gwinn and Mosher 1983). Additionally, these collections are in extremely poor shape due to the acidic nature of nineteenth-century paper, continuous poor storage conditions, and, in many cases, decade upon decade of heavy research use.

In a brittle books project, library preservation staff make title-by-title selection decisions based upon criteria that vary across projects and over time. The tendency in the beginning was to select volumes so fragile that their preservation on film most likely would be their last use. The trend today is more comprehensive selection in recognition that books on highly acidic but not-yet-brittle paper will someday need microfilming. Following filming, more and more volumes are now being returned to the shelves after some cleaning and repair, not simply because we know patrons dislike using microfilm but also because, for a given collection, books that are filmed and then discarded reside in one location (microfilm reading room storage cabinets), while those that were not filmed are browseable on the shelf or in online catalogs. These trends reflect the commitment on the part of participating libraries to balance the needs of local scholars with the demands of the national program (Child 1990). Most recently, preservation librarians have stepped up their calls for use-based microfilming as a component of the national brittle books effort (De Stephano 1995).

A central tenet of the Brittle Books Program is that no book shall be filmed twice. This rule is based upon the sound logic of economics at the national level. The need to avoid duplication has given rise to sophisticated national bibliographic control mechanisms-queuing in the Research Libraries Information Net- 
work (RLIN) and prospective cataloging in the OCLC Online Computer Library Center, Inc.'s database-that give libraries a tool for declaring their intention to create film and the time to complete the job at their own pace. The NEH requires that a bibliographic record for the master negative of each title preserved in a brittle books project be located in either RLIN or OCLC, which exchange master microfilm records on a regular basis. At least one subject heading must be included in the record.

The accomplishments of this program to date are profound and the implications are far-reaching. When the sequence of NEH grants awarded in 1995 are finished, at least 700,000 brittle volumes will have been preserved from the collections of seventy libraries throughout the nation. The present worth of this program to the taxpayers is at least $\$ 70$ million, owing to the fact that it costs roughly $\$ 100$ today to complete the microfilm reformatting of a single volume. The value of this collection will continue to grow with time as the per-volume costs of creating it increase and the availability of hard-copy duplicates decreases.

Yale University Library has been an active participant in this program since its inception; it has contributed about $10 \%$ of the total, some 72,000 volumes, counting the latest project. Beyond this contribution, the preservation surveys that laid the groundwork for the program were carried out first at Yale and then replicated across the country (Walker 1985). Gay Walker, who built the preservation program at Yale, pioneered the development of the processing procedures that are common practice today (Walker 1983). The program continues to explore ways to improve the efficiency of large-scale preservation projects-especially in the new project to preserve the content and context of the entire British History collection in the Yale library.

\section{The Intellectual Context of Selection and Subject ACCess}

Certifying the centrality and cooperative nature of selection is practically a require- ment for anyone who wishes to focus on the professional collection management responsibility of librarians and archivists. Stam (1993, p. 304), for instance, begins his excellent essay on preservation by declaring that:

Our essential purpose in preservation is to ensure the survival of evidence, incomplete and selective as it may be. The problem is one of priorities; it requires comprehensive coordination and cooperation among a broad range of institutions throughout a nation and beyond.

Practical methodologies for acting on this responsibility, however, have eluded us. A decade ago, Atkinson (1986) proposed a typology that distinguished between selection for near-term local needs and selection for long-term national purposes. "The clientele for whom this material is being preserved has not yet, for the most part, arrived on the scene," he suggested (p. 347). Cox (1989) extended and updated this typology for use in selecting archival collections for microfilming by emphasizing value and use. Child (1992) provided a handy summary of the evolution of approaches for large-scale preservation microfilming projects and pointed optimistically to the solutions expected from the ongoing work of a Commission on Preservation and Access dual task force on archival selection. Even though the task forces were unable to provide any new concrete guidance on setting specific, long-term selection priorities, the methodology for assessing collections has developed a grassroots popularity in a tremendous variety of programs nationwide (Commission 1993).

The difficulty of modeling the process of selection for preservation dogs us as we now approach the issue of selecting library materials for conversion to digital imagery. There is yet precious little discussion of the large issues; what focus there is tends toward reports on the nongeneralizable experiences of individual digital scanning projects. In pilot projects around the country, the choice of system content is largely driven by the methodology for testing the technical capabilities of conversion systems, rather than as part of a local or national strategy for converting a 
body of material for research use. This avoidance of the issue of the use and usefulness of digital imaging systems for scholarship, research, and teaching seems to be endemic to libraries. In the world of business and industry, where mission-oriented, large-scale imaging system applications originated, system design, system content, and system use go hand in hand as a matter of principle. The essential client focus and the bottom-line costs of service to these clients force this union of content and function-a union that is not so easily obtained in libraries and archives.

For us, therefore, the two essential elements of intelligent, subject-oriented selection for digital conversion from a very large corpus of literature are knowledge of the scope of the collection's content and understanding of the value of the collection (or its components) for scholarship and teaching. Beyond these essential facts, a mechanism must exist for identifying individual items within a broader topical context (Riecken 1990). Atkinson (1986, p. 350) has argued that the only practical way to accomplish large-scale cooperative preservation is to "build the program not around subjects but rather exclusively around subject collections in place." Ideally, descriptive and subject cataloging practices support these needs by facilitating both known-item retrieval and broad or narrow subject analysis, including the contextual relationships among items.

Bibliographic control of microfilm has been a challenge for the library community for decades and there is no need to recount this history (Gwinn 1987). Guidelines that have evolved since the mid1980s have codified descriptive cataloging practices and specified the mechanisms for sharing catalog data (Johnson 1995; ARL 1990). In these guidelines, discrete original items are the point of departure for cataloging microfilm masters. The assumption of all these guidelines seems to be that access to microfilm is via a knownitem search derived from information about the original item. Furthermore, present microfilm guidelines make little or no recognition of the intellectual and physical relationships within a collection and have not specified or resolved subject cataloging practice.

We know about the intense need by the scholarly community for research materials on film (Gould 1989). A recent national survey of historians found that only $7 \%$ of the entire population do not use microfilm in their work (Gordon 1992). This same population of scholars also decries the limitations on access to microfilm. Inadequate subject access is a major source of the continuing challenges associated with identifying and retrieving microfilm for purposes of digital conversion. Now, as we move toward the creation of a full-scale digital library created from a wide variety of source documents, some critics of traditional cataloging practice are beginning to suggest that we downplay full cataloging of electronic resources precisely at the point at which the Machine-Readable Cataloging (MARC) record is beginning to fulfill its potential as a universal data exchange format (Davis 1995). This would be a mistake.

If, indeed, a microreproduction is a surrogate of an original item, why should we be concerned about subject access to microfilm collections? One answer is that we know that humanities scholars are guided less by sources and more by problems and questions that lead them to particular sources (Case 1991). In their recent study of the nature of "known-item" searching, Wildemuth and O'Neill (1995) reviewed much of the literature on access points and found that between 33 and $67 \%$ of all patrons search by broad subject. Yee (1991), in an equally comprehensive review, suggests it is safe to conclude that subject searching is desired and used by our patrons, that they would make best use of a bibliographic tool that provides both controlled vocabulary and keyword text searches, and that researchers need to have online information about broader and narrower search terms, as well as information on the relationships among these terms. Markey's (1987) research on the use of classification as an access tool shows the power of preserving and displaying conceptual relationships among seemingly autonomous items. A concrete test of subject-based retrieval of a core 
topical literature from a large database also demonstrated how recall (accuracy and relevance) could be improved if researchers had ready online access to other closely related subject headings and access to other parts of the bibliographic record for subject searching (Lancaster 1991).

But what does the concept of "subject" really mean in a humanities research context? A decade of systematic research sheds light on this question, too. Bates, Wilde, and Siegfried (1993) have focused on the vocabulary of humanities research with striking results. Building on the pathbreaking work of Wiberley (1983) on historians' use of dictionaries and encyclopedias, they showed that a majority of researchers start with broad subject concepts. More importantly, humanities scholars also typically consider individual proper names to be subjects ( $45 \%$ ), as well as geographic terms (22\%), chronological eras $(16 \%)$, and disciplines (21\%). In their sophisticated evaluation of natural-language inquiries as well as formal, structured queries of online systems, they found that fully half of the study group combined general subject terms with more specific qualifiers. In yet another important study on what humanities scholars needed in the way of abstracting services, Tibbo (1993, p. 185) concluded that "facets of time, place, and specific topic are used by historians to define their search, classify their literatures, and organize college curricula."

Together, these and many related studies of search and retrieval behavior of scholars and students in the humanities suggest not only the importance of subject access, but also point toward a clear set of solutions that make full use of the bibliographic record to enhance access and support individual research (Bates 1979; 1989). None of the techniques identified will work, however, unless rich bibliographic information exists for all materials of interest to humanities researchers.

\section{A Case Study on Selection}

It was only logical, it seems now, that Yale looked to its large collection of preservation microfilm as a possibly ideal source for large-scale conversion to digital imagery. The material had already been selected for long-term preservation through an extensive local process, which was then validated at the national level; the film met the best standards of quality; and bibliographic records for each title resided in the RLIN and OCLC databases, assuring national access. As the library approached selection for digital conversion, the only questions were: What subjects were filmed and which subjects should be converted?

It is quite simple to paint an overall picture of our filming activity. In a nutshell, over the past ten years, Yale preserved on microfilm roughly fifteen thousand volumes from the American History Collection (1983-93), twenty-three thousand volumes from the European History Collection (1988-93), and nineteen thousand volumes from the History of Economics and Political Science Collection (1992-95). The Yale preservation survey team identified each of these collections as a top preservation priority. At one time, the collections were ordered on the shelf according to the "Old Yale" classification system. The classification system has a rich subject orientation and provides for subclassification by geography, historical era, and genre (Hitchcock 1953).

The selection theory was straightforward and emphasized content cohesion over the technical limitations of the digital imaging system. It called for staff to identify significant "Old Yale" subject clusters of film from each of the three major collections of interest to Yale's faculty and students in the humanities. By connecting selection with expected use, a known population of scholars could help evaluate the end product and its usefulness for scholarship. Quality control procedures worked out in earlier phases of the project (Conway and Weaver 1994) would require benchmark comparisons of digital scans from a sample of the original books (when available) with scans from the microfilm reproduction. Bibliographic records for the image version of the books would be added to our online catalog, Orbis, where they would be fully integrated with other versions of the same title and, more importantly, retrievable by scholars working 
on related or similar materials for a variety of research topics.

In the interests of project efficiency and productivity, the production plan called for converting all of the titles on entire reels of film within a given "Old Yale" subject cluster. An explicit decision was made not to "de-select" a particular title from a chosen subject cluster simply because it could not be converted easily with the equipment configuration installed at Yale. We were curious to discover the frequency and nature of "problem" books and wanted to measure the impact of these books on the conversion process. Challenges to implementing our plan fell into two broad categories: content-related issues and bibliographic control issues.

\section{ConTENT Issues}

Given the national mandate to avoid duplication, Yale did not film any volume in its collection that already had been preserved on film at another institution. Hit rates for "found film" varied within these collections from $3 \%$ to over $50 \%$. Not surprisingly, heavily used portions of a collection tend to have the highest rates of preservation film. Beyond the found film problem is the fact that many volumes in a collection were not filmed because they fell out of the date scope of the project or are modern reprints or have a lot of color content.

One partial solution to the found film challenge could be to obtain film titles for image conversion. The two options, interlibrary loan and direct purchase, require a significant investment of time and money and yield mixed results. Using "Other People's Film" takes all of the intellectual energy invested in reformatting the volume in the first place: searching for the existing film, matching records and then content, concerns about quality and completeness, and the reluctance of some libraries to loan film containing multiple titles on varying topics. More significantly, the most effective conversion of microfilm is obtained from duplicate negatives, which few libraries and archives are willing to loan.
Through most of Yale's projects, reel programming has been left to the vendor. Reel programming is the process of grouping volumes with similar characteristics, such as size and paper tone, on a reel of film that will contain about one thousand frames (as many as two thousand book pages). The admirable goals of most reel programming activity, reinforced by guidelines provided in the $R L G$ Preservation Microfilming Handbook (Elkington 1992), are to minimize film wastage, fill frames consistently, and improve the consistency of the film density across the reel. Even when programming is handled in-house, meaningful arrangement by topic is usually not a goal, and the result is intellectual chaos from reel to reel. Volumes on many different topics can and do appear on any given roll in the materials selected for Project Open Book.

In table 1 I summarize the scope of the four major brittle books microfilming projects at Yale in the past decade and describe the distribution of the preserved titles by topic on project reels. In only one project (French History) do a majority of the reels contain books on a single topic. The American History projects show the greatest dispersion of books by topic, owing in large measure to the long duration of the program and the evolution of processing procedures during the past decade.

For some key collections in a single library, most of the brittle books are now gone. As a pioneer in the nation's preservation microfilming program, Yale's procedures for handling the original book have evolved in the past decade. The discard rate for books filmed in certain areas of the European History Collection exceeds $80 \%$. The rate is partly a factor of the physical condition of the item selected for microfilming and partly determined by the overall approach taken by the bibliographer or curator responsible for preservation decision making on the collections. When filmed books are discarded, while the content is preserved, our ability to undertake quality benchmarking or to calibrate the accuracy of the scanning equipment is severely hampered. This 
TABLE 1

Yale University Librahy Microfilming Projects

\begin{tabular}{lcccc}
\hline \hline & American & European & French & Social Science \\
\hline Total volumes filmed & 15,012 & 19,645 & 3,027 & 19,000 \\
Average volumes per reel & 7.2 & 5.9 & 4,8 & 7.8 \\
Total titles filmed (est) & 11,548 & 15,148 & 2,298 & 14,600 \\
Average titles per reel & 5.6 & 4.5 & 3.6 & 7.2 \\
Total number of reels & 2,062 & 3,366 & 638 & 2,028 \\
Topical distribution of titles on reels & & & & \\
All titles on a single topic (\%) & 20 & 10 & 60 & 12 \\
Majority of titles on a topic (\%) & 36 & 75 & 29 & 44 \\
Too mixed to classify (\%) & 46 & 15 & 11 & 42 \\
\hline
\end{tabular}

calibration becomes necessary when, for whatever reason, the reduction ratio of the filmed volume is not known or seems to be inaccurately recorded. In such situations the only recourse in setting up the scanning equipment accurately is to measure the original volume, which is, of course, impossible if the original volume is in a landfill.

The end result of these four procedural matters associated with routine brittle books filming projects is a film collection at Yale with little intellectual cohesion and a devastated book collection lacking both context and comprehensiveness. Possibilities for browsing and the integrity of the original collection are lost.

Four clusters of titles in the "Old Yale" classification system were identified that contained a critical mass of microfilmed titles from the original collection and that were of interest to Yale faculty and students. These four clusters are:

- Civil War History

- Native American History

- History of Spain Before the Civil War

- History of Communism, Socialism, and Fascism

These clusters were chosen following a significant effort to reconstruct the intellectual structure of the original book collection and then identify substantial "Old Yale" subclassifications concentrated on microfilm reels with little or no extraneous material. Yale library bibliography staff played a key role in reviewing this work, assessing several years' worth of course offerings at the graduate and undergraduate level, contacting faculty in three disciplines by phone and letter, and obtaining commitments from faculty and students to use the project's digital image files for research and teaching.

\section{Bibliographic Control}

The process by which the project staff actually found the items in these subject clusters, however, raises the issue of bibliographic control of microfilm collections. When they tried to use our online catalog to undertake a comprehensive, subject-oriented analysis of microfilm holdings created in a decade of systematic filming, they encountered a number of difficulties.

Yale's earliest preservation microfilming projects made use of student assistants to undertake minimum conversion of historic card files. If no subject tracings appeared on the card, none were added and no authority control was undertaken on the converted records. During the intervening decade cataloging quality has improved but overall there remains a high level of inconsistency in the bibliographic records for preservation microfilm. Additionally, a single subject heading, whether controlled or uncontrolled, is barely sufficient to provide the kind and level of sub- 
ject access expected by today's research patrons.

When the "Old Yale" call number for the original book is included in the bibliographic record, it is located in an unsearchable local notes field (939). Each version of the microfilm itself is given one of three possible "dummy" numbers that has no intellectual value, unlike the original classification system for the brittle materials.

Without a separate, known-item search, there is no straightforward mechanism in either RLIN or Orbis to determine from the microfilm record whether the original book was returned to the shelf following filming. This fact makes it quite challenging to reconstruct the structure of the original collection without recourse to the historic shelflist, which has not been completely converted to machine-readable form and no longer contains cards for items withdrawn from the collection following filming. For better or for worse, the shelflist remains for us, along with the paperwork generated by the microfilming projects, a vital resource until retrospective conversion is complete and until Yale's microfilm cataloging procedures have been updated to make them consistent with the most enlightened cataloging practice.

Yale's challenge in finding a secondary use for microfilm collections (digital image conversion) that was not initially envisioned are emblematic of the issues that other libraries surely face. At a minimum, it is fair to assume that the library procedures followed over the years have resulted in extraordinary inconsistencies in cataloging practice that, for all intents and purposes, make the corpus of preservation microfilm in this country all but unretrievable by subject. This last statement is only the latest in a half-century string of complaints about the bibliographic control of microfilm (Gwinn 1987).

\section{RECOMMENDATIONS TO IMPROVE SUbJect ACCess at THE Local INSTITUTION}

Librarians engaged in comprehensive preservation microfilming projects can take a number of concrete steps immediately to make sure that the end product of their work is manageable as a discrete, meaningful collection and that the structure and content of the original collection is preserved and at least minimally retrievable by topical concepts.

1. Undertake broad and comprehensive subject cataloging of microfilm masters using as many fields of the USMARC record as are appropriate to capture rich information about each item's content in terms of time, space, and topic. Multiple controlled subject terms, including broad and narrow related terms, are a must.

2. Record format information in fully searchable fields in the local catalog, as well as in national bibliographic utilities.

3. Record standardized information on brittle books projects in a fully searchable field. The unique identifier assigned by $\mathrm{NEH}$ to the project might be an appropriate place to begin.

4. Record information about the existence of microfilm of books created by other research libraries in a fully searchable field in the local catalog. This is the present practice at Harvard University Library for all grantfunded projects.

5. Record identifying information about the existence of the original item in the bibliographic record for the microfilm, if the book was retumed to the shelf after preservation processing.

6. Program entire reels of microfilm by narrowly defined topic, to improve the possibilities for browsing of the microfilm collection.

With comprehensive bibliographic control and creative reel programming, a local collection of microfilmed books could be made as readily accessible and as amenable to browsing as a collection of books. These recommendations (as well as some forthcoming ones relating to the technical characteristics of preservation film) ought to become standard preservation processing procedures. 


\section{RECOMMENDATIONS FOR BUILDING THE DIGITAL LIBRARY WTTH MICROFILM}

The Brittle Books Program is creating the first "virtual library" in the world that also happens to be a vital source for digital conversion. This library is largely underground and exists as an "entity" only in national bibliographic databases; yet, when completed, its size and scope will rival the collections of many major research libraries in this country. We owe it to present and future scholars (to say nothing of the taxpayers who foot the bill) to make it fully accessible to patrons as a complex collection with many facets, many uses, and many points of access. Thus, selecting from this national collection of microfilm to help create part of the new national digital library becomes, by nature of the conditions of its creation, a responsibility that transcends the collection development and preservation policies of any of the libraries that have participated in the Brittle Books Program to date. Here is a set of recommendations for making broad, subject-oriented selections from one virtual library to create another.

1. Approach the selection process as a discipline-based, multi-institution, multiformat collection development program (Hazen 1995).

2. Identify the core literature in the target discipline using techniques used at Cornell University in the ongoing agricultural literature project (Demas 1994).

3 . Use the core literature as the seed for "growing the pearl," which is far more extensive than the core and far more varied than published sources on paper or film (Bates 1979).

It is important to emphasize that neither a core collection in electronic form nor a demand-driven digital conversion program is a sufficient model for building the digital library. The weaknesses of each approach can only be overcome by developing a richer process that retains the intellectual cohesiveness of the core collection concept and the value validation that patterns of patron use provide. The criterion for initially enlarging the digital collection around the core literature should be recent use of either a microfilmed book in one library or the paper original in another library, as determined by circulation, refiling, and loan statistics from participating institutions. The criterion for adding books beyond those that have recently circulated should be topical relevance, as determined by broad-based subject analysis of already-preserved materials. Finally, the criterion for adding special collections material, especially unpublished archives and manuscripts, to this enlarged kernel of digital resources should be scholarly demand for access to microfilmed collections, as determined by reproduction and loan requests.

The approach outlined here for building a digital library from microfilm of the nation's most important brittle books places collection managers under the same umbrella with other parties interested in creating and then preserving the availability of digital resources. At the heart of this comprehensive selection strategy is a richer understanding of the use of research materials than we have known in the past. And yet this understanding is absolutely essential because without factoring our patrons into the decision-making process, the risk of failure is simply too high. The approach is present-tense oriented but recognizes that digital preservation involves nearly continual reappraisal of the value of the electronic collection (Conway 1994). The bottom line for all of us, however, may well be that, without improvements in intellectual access to microfilm collections that support subject-oriented retrieval, digital conversion of these collections may prove to be quite feasible technically and quite untenable intellectually.

The lessons from Project Open Book about selection of microfilm point to very concrete and achievable solutions for everyone involved in preservation microfilming and the digital conversion of that film. Other findings from Project Open Book demonstrate the extraordinary quality of digital imagery that can be achieved by converting second-generation micro- 
film. This conclusion reaffirms the general accuracy of the technical standards that govern preservation microfilm and the value of the guidelines that interpret these standards. More significantly, the findings on conversion quality also will establish the fundamental place of microfilm for both preservation and access. This is a liberating notion for the digital library we are just beginning to build and should allow us now to concentrate our energies on preserving this new "virtual" library, confident that microfilm could serve as a viable backup source.

\section{WORKS CITED}

Association of Research Libraries. 1990. Guidelines for bibliographic records for preservation microform masters. Washington, D.C.: Association of Research Libraries.

Atkinson, Ross. 1986. Selection for preservation: A materialistic approach. Library resources \& technical services 30: 341-53.

Bates, Marcia J. 1979. Information search tactics. Journal of the American Society for Information Science 30: 205-14.

. 1989. Rethinking subject cataloging in the online environment. Library resources \& technical services 33: 400-12.

Bates, Marcia J., Deborah N. Wilde, and Susan Siegfried. 1993. An analysis of search terminology used by humanities scholars: The Getty online searching project report number 1. Library quarterly 63: 1-39.

Case, Donald Owen. 1991. The collection and use of information by some American historians: A study of motives and methods. Library quarterly 61: 61-82.

Child, Margaret. 1990. Selection for microfilming. American archivist 53: 250-55.

- 1992. Selection for preservation. In Advances in preservation and access. Vol. 1. Ed. Barbra Buckner Higginbotham and Mary E. Jackson. Westport, Conn.: Meckler, 147-58.

Commission on Preservation and Access. 1993. Preservation of archival materials: A report of the task forces on archival selection to the Commission on Preservation and Access. Washington, D.C.: Commission on Preservation and Access.

Conway, Paul. 1994. Digitizing preservation: Microfilm and paper go electronic. Libraryjournal 119: 42-45.

Conway, Paul, and Shari Weaver. 1994. The setup phase of Project Open Book. Wash- ington, D.C.: Commission on Preservation and Access.

Cox, Richard J. 1989. Selecting historical records for microfilming: Some suggested procedures for repositories. Library \& archival security 9: 21-41.

Davis, Stephen Paul. 1995. Digital image collections: Cataloging data model \& network access. Internet document available at: http://www.columbia.edu/cu/libraries/ins ide/projects/diap/paper.html

Demas, Samuel. 1994. Setting preservation priorities at Mann Library: A disciplinary approach. Library hi tech 12, no.3: 81-88.

De Stephano, Paula. 1995. Use-based selection for preservation microfilming. College \& research libraries 56: 409-18.

Elkington, Nancy E. 1992. RLG preservation microfilming handbook. Mountain View, Calif.: Research Libraries Group.

Farr, George F. 1992. NEH's program for the preservation of brittle books. In Advances in preservation and access, vol. 1, eds. Barbra Buckner Higginbotham and Mary E. Jackson. Westport, Conn.: Meckler, 49-60.

Gordon, Ann D. 1992. Using the nation's documentary heritage: The report of the Historical Documents Study. Washington, D.C.: National Historical Publications and Records Commission.

Gould, Constance. 1989. Information needs in the humanities: An assessment. Stanford: Research Libraries Group.

Gwinn, Nancy E. 1987. Preservation microfilming: A guide for librarians and archivists. Chicago: ALA.

Gwinn, Nancy E., and Paul H. Mosher. 1983. Coordinating collection development: The RLG conspectus. College \& research libraries 44: 128-40.

Hazen, Dan C. 1995. Collection development policies in the information age. College d research libraries 56: 29-31.

Hitchcock, Jennette E. 1953. The Yale library classification. Yale University library gazette 27: 95-109.

Johnson, Bruce C., ed. 1995. Guidelines for bibliographic description of reproductions. Chicago: ALA.

Lancaster, F. W., and others. 1991. Identifying barriers to effective subject access in library catalogs. Library resources \& technical services 35: 377-91.

Markey, Karen. 1987. Searching and browsing in the Dewey Decimal Classification in an online catalog. Cataloging \& classification quarterly 7: 37-68.

Riecken, Henry. 1990. The agony of choice: Strategies for preservation and scholar- 
ship. In Annual report 1989-90. Washington, D.C.: Commission on Preservation and Access, 7-13,

Stam, David H. 1993. The questions of preservation. In Research libraries-Yesterday, today, and tomorrow, ed. William J. Welsh. Westport, Conn.: Greenwood Press, 303-18.

Tibbo, Helen. 1993. Abstracting, information retrieval and the humanities: Providing access to historical literature. ACRL publications in librarianship, no, 48. Chicago: ALA.

Walker, Gay, 1983. Preserving intellectual content of deteriorated library materials. In The preservation challenge: A guide to conserving library materials, ed. Carolyn Clark Morrow. White Plains, N.Y.: Know]edge Industry Publications, 93-113.

Walker, Gay, and others. 1985. The Yale survey: A large-scale survey of book deterioration in the Yale University Library. College \& research libraries 46: 111-32.

Waters, Donald J. 1991. From microfilm to digital imagery. Washington, D.C.: Commission on Preservation and Access.

Waters, Donald J., and Shari Weaver. 1992. The organizational phase of Project Open Book. Washington, D.C.: Commission on Preservation and Access.

Wiberley, Stephen E., Jr. 1983. Subject access in the humanities and the precision of the humanists' vocabulary. Library quarterly 53: 420-33.

Wildemuth, Barbara M., and Ann L. O'Neill. 1995. The "known" in known-item searches: Empirical support for user-centered design. College \& research libraries 56: $265-81$.

Yee, Martha M. 1991. System design and cataloging meet the user: User interfaces to online public access catalogs. Journal of the American Society for Information Science 42: 78-98.

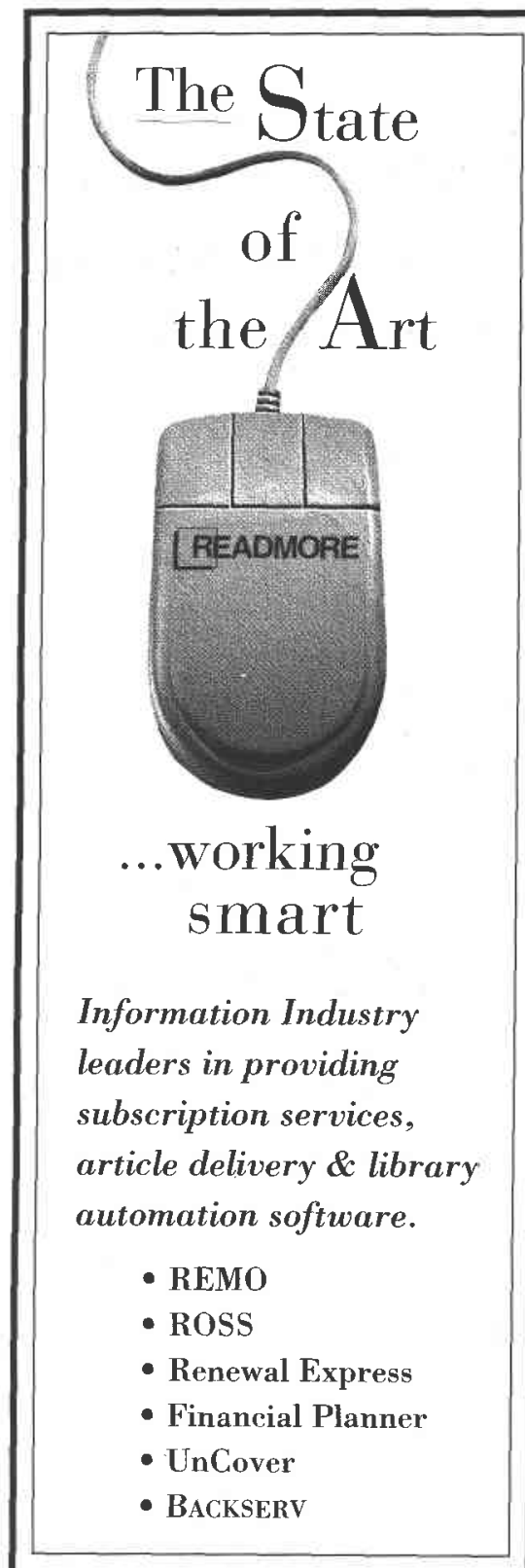

ReAdMore ACADEMIC SeRVICES

700 Black Horse Pike, Ste. 207

Blackwood, NJ 08012

Phone: 1-800-645-6595

Fax: 609-227-8322 